DOI: 10.12731/2658-4034-2020-1-76-84

\title{
СТАНОВЛЕНИЕ КОМПЕТЕНТНОСТНОГО ПОДХОДА В СИСТЕМЕ РОССИЙСКОГО ВЫСШЕГО ОБРАЗОВАНИЯ
}

\author{
Шехмирзова А.М., Грибина Л.В.
}

ФГБОУ ВО «Адыгейский государственный университет»,

г. Майкоп, Республика Адыгея, Российская Федерация

В статье представлен анализ развития компетентностного подхода в системе россиисккого высшего образования. Выделены и обобщены этапы становления компетентностного подхода. Показана семантическая многозначность проблематики компетентностного подхода.

Ключевые слова: компетенция; компетентностный подход; высшее образование; Болонский процесс; этапь становления.

\section{FORMATION OF A COMPETENCY-BASED APPROACH IN THE SYSTEM OF RUSSIAN HIGHER EDUCATION}

\section{Shekhmirzova A.M., Gribina L.V.}

Adyghe State University, Maikop, Adygea Republic, Russian Federation

The article presents an analysis of the development of the competency-based approach in the system of Russian higher education. The stages of formation of the competency-based approach are highlighted and generalized. The semantic polysemy of the problems of the competency-based approach is shown.

Keywords: competence; competency-based approach; higher education; Bologna process; stages offormation.

Произошедшие системные изменения в российском образовании в условиях Болонского процесса определили новые ориенти- 
ры в организации уровневого обучения в высшей школе с учетом международного опыта. Введение в России уровневого высшего образования направлено, в первую очередь, на содействие гармонизации российской и общеевропейской образовательных систем с взаимным признанием дипломов выпускников высших школ.

Обращение в ходе исследования к истории возникновения компетентностного подхода в системе российского образования позволило нам выявить его сущностные особенности. Наиболее удачное представление общих этапов становления компетентностного подхода предложено И.А. Зимней. На основе анализа и обобщение работ различных ученых (И.А. Зимняя, Д. Хаймс, Н. Хомский, Дж. Равен, Н.В. Кузьмина, А.К. Маркова, Л.И. Берестова, В.И. Байденко, А.В. Хуторской и др.) можно условно выделить несколько этапов, представляющих интерес для нашего исследования. Причем выделенные авторами этапы нами дополнены и дальше развиты.

Первый этап (1960-1970 гг.) связан с введением в научный аппарат категории «компетенция», созданием предпосылок разграничения понятий компетенция/компетентность, появлением их разновидностей («коммуникативная компетентность» по Д. Хаймсу), исследование различных видов языковой компетенции в русле теории грамматики и обучения языкам (исследования Н. Хомского). Именно в общем контексте исследований компетенции, проведенного Н. Хомским в Массачусетском университете в рамках теории языка и трансформационной грамматики, в 1965-1970 гг. в США было сформировано образование с ориентацией на компетенции (competence - based education).

Bторой этап (1970-1990 гг.) характеризуется использованием категорий компетенция/компетентность в теории и практике обучении различным предметам, расширением их использования («социальная компетентность»), а также распространением в отдельных сферах жизнедеятельности: в управлении, руководстве, менеджменте, в обучении общению. В этот период особую значимость в развитии компетентностного подхода имела работа известного английского психолога Джона Равена «Компетентность в современ- 
ном обществе: выявление, развитие и реализация» (London,1984) [1]. Работа известного ученого является актуальной и в настоящее время. Отдельные его положения оказали положительное влияние на исследовательские позиции авторов, способствуя более глубокому пониманию сущности компетентностного подхода.

Tретий этаn (1990-2001 г.г.) характеризуется появлением исследовательских работ в различных областях научного знания. Среди них особое значение имели работы А.К. Марковой $(1993,1996)$, в которых предметом специального всестороннего рассмотрения исследователя стала профессиональная компетентность в общем контексте психологии труда. Также широко, но вместе с тем не в контексте целей и результатов образования, используется категория «компетентности» в исследованиях других отечественных ученых Н.В. Кузьминой и Л.А. Петровской. На этом этапе в материалах и документах ЮНЕСКО очерчивается круг компетенций, которые уже должны рассматриваться всеми как желаемый результат образования.

В ходе дальнейшего развития в истории российского образования, как показал проведенный анализ научно-педагогической литературы, происходило переосмысление компетентностного подхода, схождением большинства исследователей во мнении, что он позволяет оптимально сочетать и интегрировать теоретическую и практическую составляющие обучения. При этом происходило переосмысление места и роли теоретических знаний в процессе освоения компетенций, их упорядочение и систематизация, овладение теоретическими и практическими знаниями в комплексе, что, в конечном счете, приводило к повышению мотивации обучающихся в их освоении.

Значительным шагом в развитии компетентностного подхода в российском образовании стало введение определения «ключевых компетенций» (key competencies) как наиболее универсальных по своему характеру и степени применимости. Такая необходимость была озвучена на симпозиуме в Берне в 1996 году по программе Совета Европы [2]. На симпозиуме отмечалась значимость приобретения ключевых компетенций обучающимися для успешной работы и получения в дальнейшем высшего образования. Также подчер- 
кивалось, что формирование ключевых компетенций определяется социальной средой, в связи с чем, для каждой страны их перечень может стать различным. Понимание этих понятий в России и в Европейском союзе несколько различалось. В работах В. Хутмахера приводятся принятые Советом Европы определения пяти ключевых компетенций, овладение которыми необходимы для молодых европейцев [6]. Ключевые компетенции наполняются другим смысловым содержанием в исследованиях академика Международной педагогической академии А.В. Хуторского, в составе которых представлены: ценностно-смысловые, общекультурные, учебно-познавательные, информационные, коммуникативные, социально-трудовые, личностного самосовершенствования. Этот перечень был представлен ученым в своем докладе «Определение общепредметного содержания и ключевых компетенций как характеристика нового подхода к конструированию образовательных стандартов» и обсуждался в октябре 2002 года на Отделении философии образования и теоретической педагогики РАО [5].

В решении проблемы ключевых компетенций существенное различие наблюдается в подходах их отбора, применяемых в странах Евросоюза и в России. Решение задачи разработки номенклатуры ключевых характеристик в Европейских странах основано на анализе социальных требований общества к выпускникам высшей школы и запросов работодателей. В докладе Международной комиссии по образованию ЮНЕСКО «Образование сокрытое сокровище» (1997) отмечалось, что все чаще предприниматели испытывают потребность в компетентности как своеобразного коктейля навыков, присущих отдельно взятому индивиду в сочетании с квалификацией, соответствующей социальному поведению, способностью работать в коллективе, инициативности к рискам. Определенные Советом Европы пять основных ключевых компетенций, овладение которыми значимо для молодых европейцев, представлены В. Хутмахером. В их состав входят перечень политических и социальных компетенций; компетенций, связанных с жизнью в многокультурном обществе; компетенций, относящихся к овладению устной и письменной 
коммуникацией; компетенцией, связанных с возрастанием информатизации общества; компетенцией как способности обучаться на протяжении жизни [6]. В России основой выбора ключевых компетенций в разные периоды становились личные пристрастия отдельных исследователей и прямой перенос зарубежного опыта в практическую реальность без анализа и учета культурно-исторического опыта и современной социально-экономической ситуации.

Можно выделить четвертый и последующие этапь (с 2001 г.) дальнейшего становления компетентностного подхода, характеризующиеся постепенным его превращением в общественно значимое явление, претендующее на роль концептуальной основы политики в сфере образования на государственных и международных уровнях. Причиной этому послужило то, что в российском образовании, как и в образовании стран Евросоюза, давно назрела необходимость получения нового качества образовательных результатов. В дальнейшем, компетентностный подход вводится в содержание образовательных стандартов, происходит переход России на компетентностно-ориентированное образование в соответствии с правительственной Программой модернизации российского образования до 2010 года, подтвержденной решением Коллегии Минобрнауки РФ «О приоритетных направлениях развития образовательной системы Российской Федерации» в 2005 году. На заседании Президиума Учебно-методического совета по философии, политологии и религиоведению МГУ им. М.В. Ломоносова в ноябре 2005 года в рамках обсуждения вопросов реализации Болонского процесса было утверждено содержание понятия «компетенция». В документах данного заседания было зафиксировано, что компетенция является предметной областью, в которой индивид должен быть хорошо осведомлен и проявлять готовность к выполнению деятельности, а «компетентность» - интегрированная характеристика качеств личности, выступающая как результат подготовки выпускника для выполнения деятельности в определенных областях. Иными словами, в тот период при определении понятия исходили из соответствия между компетенцией и знаниями, а также между компетентностью и умениями (действиями). 
В современных условиях становления компетентностного подхода в российской системе образования, смысловые характеристики данного понятия расширяются в науке и в сфере профессиональной деятельности. Появляются новые словосочетания и термины, обусловленные семантической многозначностью проблематики компетентностного подхода. По мнению ряда известных исследователей (Б.С. Гершунского, А.И. Ракитова и др.) появление новых сочетаний понятий составляет своеобразное «научное поле», в уточнении значений употребляемых дефиниций, их структурирования и создания вначале «категориального каркаса», затем научной теории и возможностей ее практической реализации. Такой способ становления теоретического знания в науке называют «категориальным синтезом». Подобным образом, на основе выявления сущности понятий, составляющих «категориальный каркас» компетентностного подхода, возможна разработка его теории и технологии практической реализации. Решение данной задачи требует проведения отдельного исследования. Вместе с тем, в рамках проводимого исследования по мере раскрытия рассматриваемых вопросов, будем касаться понятийного поля компетентностного подхода, выделять наиболее значимые категории и проводить теоретико-методологический анализ.

Вхождение компетентностного подхода в российскую науку и образовательную практику сопровождалось многочисленными исследованиями ученых и исследовательских коллективов, изучение которых позволило вникнуть в сущность и обратиться к анализу смыслообразующих его категорий.

По мнению Джона Равена, одного из британских основоположников компетентностного подхода, в содержание термина «компетентность» («competence») уже на начальном основании входят новые компоненты, не составляющие объём понятия «умения, которому научают».

Как отмечает в своих исследованиях S.A. Whiddett, зачастую на практике, объединяют понятия «компетенции» и «компетентности». Однако, более типичным является описание компетенций во взаи- 
мосвязи со способностями, которые больше отражают стандарты поведения, чем характеризуют решение определенных задач или результаты выполненной работы [7]. В русском переводе руководства по компетенциям, С. Уиддетт и С. Холлифорд, различая эти два понятия, пишут о передаваемых ими смыслах [4]. Под компетентностью понимается способность личности, необходимая ей при решении рабочих задач и позволяющая получить необходимые результаты работы. Компетенция определяется в виде способности, отражающей необходимые стандарты поведения. Очевидно, что в таком аспекте, понятие «способность» входит в противоречие с русским его словоупотреблением в смысле потенциальной сущности, тогда как стандарты поведения отражают актуальную сущность.

По мнению итальянского исследователя Ф. Цивелли, можно выделить разные способы понимания того, что называется компетентностью. Для североамериканцев привычно связывать компетентность с базовыми характеристиками человека, которые обусловливают его выдающиеся успехи в определенных видах деятельности. В континентальной Европе компетентность чаще связывают со способностями, личностными чертами и приобретенными знаниями. Особняком, как обычно, стоит Великобритания, где преобладает мнение, что компетентность должна определяться как соответствие результатов деятельности индивида сложившимся стандартам. Дальнейшие исследования позволили выяснить, что сами компетентности представляют многоуровневую структуру. Так, Д. Шон в своей известной книге «Рефлексивный практик» попытался построить «действенно-ориентированную модель» компетентности в противовес технически рациональному подходу.

Как отмечают Л.М. Спенсер, С.М. Спенсер знание является сложной компетенций. Как отмечают исследователи в своей работе «Компетенции на работе [3]. Модели максимальной эффективности работы» баллы за тесты на знания зачастую не в состоянии прогнозировать исполнение работы, поскольку не могут измерить то, как знания и навыки используются в работе. Глубинные компетенции (мотивы и свойства), лежащие в основе айсберга личности, 
оценить и развить труднее; рентабельнее отбирать людей по наличию этих характеристик.

\section{Список литературы}

1. Джон Равен Компетентность в современном обществе: выявление, развитие и реализация. М.: Когито-Центр, 2002. 400 с.

2. Совет Европы: Симпозиум по теме «Ключевые компетенции для Европы»: док. DECS / SC / Sec. (96) 43. Берн, 1996.

3. Спенсер Л.М., Спенсер С.М. Компетенции на работе. Модели максимальной эффективности работы. Пер. с англ. М: НІРРО, 2005. $384 \mathrm{c}$.

4. Уиддет С., Холлифорд С. Руководство по компетенциям. Пер. с англ., М.: ГИППО, 2008. 228 с.

5. Хуторской А.В. Ключевые компетенции и образовательные стандарты (Доклад на Отделении философии образования и теоретической педагогики РАО) // Интернет-журнал «Эйдос». 2002. 23 апреля. http://eidos.ru/journal/2002/0423.htm

6. Hutmacher Walo Key competencies for Europe // Reportof the Symposium Berne, Switzerland 27-30 March, 1996. Council for Cultural Cooperation a Secondary Education for Europe. Strasburg, 1997.

7. Whiddett S., Hollyford S. Practical guide to competencies. London: Chartered Institute of Personnel and Development. 2006.

\section{References}

1. Dzhon Raven Kompetentnost'v sovremennom obshchestve: vyyavlenie, razvitie i realizatsiya. M.: Kogito-Tsentr, 2002. 400 p.

2. Sovet Evropy: Simpozium po teme «Klyuchevye kompetentsii dlya Evropy»: dok. DECS / SC / Sec. (96) 43. Bern, 1996.

3. Spenser L.M., Spenser S.M. Kompetentsii na rabote. Modeli maksimal'noy effektivnosti raboty. Per. s angl. M: HIPPO, 2005. 384 p.

4. Uiddet S., Kholliford S. Rukovodstvo po kompetentsiyam. Per. s angl., M.: GIPPO, 2008. 228 s.

5. Khutorskoy A.V. Klyuchevye kompetentsii i obrazovatel'nye standarty (Doklad na Otdelenii filosofii obrazovaniya i teoreticheskoy pedagogi- 
ki RAO) // Internet-zhurnal «Eydos». 2002. 23 aprelya. http://eidos.ru/ journal/2002/0423.htm

6. Hutmacher Walo Key competencies for Europe // Reportof the Symposium Berne, Switzerland 27-30 March, 1996. Council for Cultural Cooperation a Secondary Education for Europe. Strasburg, 1997.

7. Whiddett S., Hollyford S. Practical guide to competencies. London: Chartered Institute of Personnel and Development. 2006. 